\title{
Entre amas de leite, especialistas, mães e creches: concepções sobre bebês no Brasil
}

\author{
Among wet nurses, experts, mothers and day cares: conceptions of babies in Brazil
}

Entre nodrizas, expertos, madres y guarderías: concepciones sobre bebés en Brasil

\author{
CARolina Machado CASTElli* \\ ANA CRISTINA COLL DELGADO**
}

\begin{abstract}
RESUMO
Este artigo é um ensaio decorrente de pesquisa teórica a respeito de concepções sobre bebês na realidade brasileira. O principal objetivo é discutir ideias sobre os bebês que têm circulado no Brasil, desde séculos passados, e que ainda têm desdobramentos hoje. O estudo é baseado em autores da História da Infância e dos Estudos da Infância. São discutidas quatro das muitas concepções sobre bebês: o bebê das amas de leite; o bebê dos especialistas; o bebê das mães; e o bebê das creches. A partir disso, são traçadas reflexões acerca da problemática no contexto atual, sendo perceptível que esses conceitos influenciam o panorama contemporâneo, o qual, por sua vez, difere bastante de séculos passados. Perceber outras realidades, identificar as concepções acerca dos bebês e prestar atenção em suas ações são condutas que permitem conhecê-los melhor, lutar por seus direitos e propor práticas que salientem e potencializem suas capacidades.
\end{abstract}

Palavras-chave: Bebês. História da Infância. Pedagogia.

\begin{abstract}
This article is an essay that results from a theoretical research on conceptions of babies in the Brazilian reality. Its main objective is to discuss conceptions about babies that have circulated in Brazil since past centuries and still have ramifications in our society. The study is based on History of Childhood and Childhood Studies authors. The article discusses, among many conceptions of babies, four of them: the baby of the wet nurses; the baby of the experts; the baby of the mothers; and the baby of day care centers. From this, reflections regarding the problem in the current context are drawn, highlighting that these ideas influence the contemporary scene, which, in turn, differs greatly from past centuries. Knowing other realities, identifying the conceptions we have about babies and watching the actions they perform allows us to know them better, fight for their rights and propose practices that highlight and boost their capacities.
\end{abstract}

Keywords: Babies. History of Childhood. Pedagogy.

\begin{abstract}
RESUMEN
Este artículo es resultado de una investigación teórica sobre las concepciones sobre los bebés en la realidad brasileña. El principal objetivo es discutir las ideas acerca de los bebés que han estado circulando en Brasil desde los siglos pasados y aún afectan nuestra sociedad. El estudio se basa en autores de la Historia de la Niñez y Estudios de la Niñez. Cuatro de las muchas concepciones de los bebés son discutidas: el bebé de las nodrizas; el bebé de los expertos; el bebé de las madres; y el bebé de las guarderías. A partir de esto, se reflexiona sobre el tema en el contexto actual, siendo evidente que estas concepciones influyen en la escena contemporánea, que, a su vez, es muy diferente de los siglos pasados. Conocer otras realidades, identificar las concepciones que tenemos sobre los bebés y prestar atención a las acciones que ellos realizan nos permite conocerlos mejor, luchar por sus derechos y proponer prácticas que enfatizan y potencian sus capacidades.
\end{abstract}

Palabras clave: Bebés. Historia de la Infancia. Pedagogía.

\footnotetext{
* Doutoranda no Programa de Pós-Graduação em Educação da Universidade Federal de Pelotas - UFPEL e Pedagoga no Núcleo de Desenvolvimento Infantil da Universidade Federal de Santa Catarina-NDI/UFSC.E-mail: <m.carolinacastelli@gmail.com>.

**Graduada em Pedagogia, com especialização em Educação pela Universidade Federal de Pelotas - UFPEL. Mestre em Educação pela Universidade Federal de Santa Catarina - UFSC. Doutora em Educação pela Universidade Federal Fluminense - UFF, com estágio doutoral no Instituto de Estudos da Criança da Universidade do Minho, Braga, Portugal. Pós-doutorado na Universidade de Caen, no Centro de Ciências da Educação - França. E-mail: <anacoll@uol.com.br>.
} 


\section{PARA COMEÇAR: O BEBÊ É UMA PESSOA}

A história da humanidade abordada nas escolas de ensinos fundamental e médio retrata, além da trajetória do branco, ocidental e católico, a história criada pelos adultos e sobre os adultos. A História da Infância, trabalhada em nível superior, nos cursos de Pedagogia, muito tem contribuído para os estudos nessa área, embora sejam mais esparsos os registros históricos sobre a vida dos bebês. O que provavelmente tenha repercutido nas concepções acerca deles e no trabalho nas creches, sendo ambos, bebês e profissionais, encarregados da sua educação e cuidado, desvalorizados perante as outras etapas educacionais e políticas públicas.

É inquestionável que os bebês passaram a ser valorizados como sujeitos de direitos desde a Declaração dos Direitos da Criança (ONU, 1959), o que foi se desenvolvendo até a Convenção sobre os Direitos da Criança (ONU, 1989) e provocando desdobramentos na legislação brasileira, principalmente, pelo ECA Estatuto da Criança e do Adolescente (BRASIL, 1990). Neste consta que a infância dura até os doze anos de idade. Porém, com relação aos bebês e às crianças bem pequenas, há muito por fazer. Para Sarmento (2004), são mais complexas as condições de existência das crianças, mesmo com a crescente afirmação dos seus direitos. Conforme argumenta o autor, aprofundaram-se as desigualdades sociais entre as crianças, e acrescentase que, entre os bebês, estas são mais profundas quando somadas à pobreza, a doenças, guerras, violência, entre outras calamidades.

Neste artigo, recorte de uma dissertação da área da educação, discutem-se, com apoio de autores da História da Infância e dos Estudos da Infância, concepções de bebês existentes na realidade brasileira, desde séculos passados, e que ainda têm desdobramentos hoje, na sociedade. Como algumas perspectivas e práticas ultrapassam as fronteiras territoriais, havendo estudos internacionais aprofundados e com relevantes contribuições acerca do tema, recorre-se também a estes. Pelas contribuições da História, percebe-se o quanto as práticas vão sendo modificadas (ou não) ao longo do tempo e uma das razões para tal é o interesse de certos grupos sociais.

Não é essencial, aqui, demarcar datas específicas, somente situar em que período os recortes se encontram, visto que as práticas vão se tornando recorrentes ou caindo em desuso com o passar dos anos e, às vezes, dos séculos. Através dos recortes apresentados no artigo, é possível pensar os bebês vistos sob esses vieses, o que não implica unanimidade, mas, sim, que algumas ideias marcaram e continuam marcando profundamente a sociedade. $\mathrm{O}$ que se considera "bebês", nesta escrita, corresponde às pessoas de pouca idade que apresentam determinadas características culturais. Estas vão além de delimitações etárias rígidas e permitem que eles se compreendam e sejam compreendidos como tais. Características, como formas corporais, modos de participação na sociedade, habilidades, brincadeiras e linguagens, que variam a cada grupo social e, portanto, relacionam-se com os bebês também de formas variadas e particulares (ROGOFF, 2005).

Tanto Rogoff (2005) quanto Pino (2005) compreendem o desenvolvimento humano (portanto, também a aprendizagem) como um processo cultural, que vai além do biológico. Tanto o fator biológico quanto a cultura marcam o desenvolvimento dos indivíduos, que possuem um equipamento biogenético e neurológico carregado por uma herança cultural, conferindo-lhes a possibilidade de serem seres culturais e se desenvolverem através de formas de participação em atividades socioculturais.

A cultura, nessa perspectiva, engloba todas as produções humanas (resultado da vida social e da atividade social), as quais são constituídas por um componente material, dado pela natureza, e por um simbólico, dado pelo homem (PINO, 2005). Por isso, os bebês, assim como as demais crianças, são considerados sujeitos da infância e produtores de culturas que não são alheias às adultas. Mas possuem modos específicos de existência devido às maneiras exóticas de comunicação, quando vistas em relação às dos adultos (GOTTLIEB, 2009).

Os bebês também podem ou, melhor, precisam ser considerados, a partir das legislações supracitadas, como merecedores de direitos. Diversos autores e estudiosos da área (WINNICOTT, 1975; DOLTO, 1985; ROGOFF, 2005; GOTTLIEB, 2009; MOZÉRE, 2012, 2013) têm afirmado, desde o século XX, que o bebê é uma pessoa. Tal declaração possivelmente tenha relações com o avanço dos direitos das crianças a partir da Segunda Guerra Mundial, além de sugerir que os bebês não precisam andar, falar, ou atingir estágios do desenvolvimento e da aprendizagem, para se tornarem pessoas. Afinal, desde seus primeiros momentos de ingresso no mundo, demonstram possuir um grande potencial biológico, cultural e relacional, sobre o qual se precisa aprender mais.

Prestando-se atenção nos bebês, com um olhar menos adultocêntrico ${ }^{1}$, pode-se constatar o quão complexo eles são e competentes em se expressar, estabelecer contatos com outras crianças e adultos e compreender o mundo.

\footnotetext{
Este olhar adultocêntrico, ou melhor, o adultocentrismo, é uma ideia proposta, no Brasil, primeiramente por Rosenberg (1976), indicando a centralidade, ou melhor, uma suposta superioridade, dada pelos próprios adultos ao que lhes diz respeito, quando em comparação com as outras idades/gerações - tal como o etnocentrismo se impõe com relação às outras etnias (ROGOFF, 2005). Visões adultocêntricas não estão interessadas em conhecer as crianças por elas mesmas e para elas mesmas, mas são veiculadas através das mídias, das práticas, das conversas, das concepções dominantes e legitimadas de conhecimento, privilegiando o saber e o fazer dos adultos em detrimento do saber e fazer das crianças.
} 
Recentes pesquisas têm confirmado que os bebês têm capacidade de resolver problemas e se colocar no lugar do outro (CUZZIOL, 2013), gostam de desafios (FOCHI, 2013), brincam incorporando elementos culturais (SCHMITT, 2008) e aprendem a partir de suas experiências e interações.

Por conseguinte, o caráter de inferioridade e prematuridade que a sociedade historicamente atribuiu aos bebês não representa uma perda ou um obstáculo para eles - pelo contrário, é um enorme ganho e possibilidade de desenvolvimento, pois é o que lhes permite serem educados e beneficiados pela experiência cultural humana. Nas palavras de Pino, "a aparente desvantagem em termos biológicos constitui uma vantagem em termos culturais" (2005, p. 47). Entretanto, a concepção de um bebê hábil, capaz, que se relaciona e que já faz parte da cultura, inclusive recriando-a, não é preponderante em nossa sociedade, até porque, no Brasil, ela tem circulado com mais força somente recentemente.

A indagação que se faz e que motivou esta escrita busca entender quais seriam as concepções hegemônicas sobre os bebês que os adultos foram construindo ao longo da história e que, de certa forma, impediram que eles fossem considerados como pessoas, para além de lactentes. Este ensaio, voltado para os olhares dos adultos sobre os bebês, pode contribuir para que se pense nos discursos que ainda circulam no século XXI, posto que não há uma linearidade histórica na construção dessas ideias: elas vão e voltam, encontram-se e se desencontram, nas imagens da mídia, na literatura sobre os bebês, nas representações dos adultos e das crianças maiores. Nesse sentido, as tentativas de traçar algumas dessas concepções são um recurso para que perspectivas sobre os bebês ainda presentes nas instituições coletivas e na sociedade sejam enfrentadas.

Essas concepções foram organizadas em quatro seções: o bebê das amas de leite; o bebê dos especialistas; o bebê das mães; e o bebê das creches. Finalizou-se traçando algumas reflexões acerca da problemática no contexto atual, sendo perceptível como tais ideias, de séculos anteriores, influenciam o panorama contemporâneo, o qual, por sua vez, difere bastante de panoramas anteriores. Propõe-se, ainda, o desafio de que se possa conhecer outras realidades, refletir sobre as práticas e prestar atenção nas ações que os bebês realizam. Ao conhecê-los melhor, pode-se compreender a importância de lutar pelos seus direitos e propor práticas que salientem e potencializem suas capacidades.

\section{O BEBÊ DAS AMAS DE LEITE}

\author{
Badinter (1985), Civiletti (1991), Almeida (1999) \\ e Donzelot (1986) revelam que, tanto na Europa
}

como no Brasil, nos séculos XVII e XVIII, assim que nasciam, os bebês eram entregues para serem cuidados por amas de leite e permaneciam com elas até que completassem seis anos de idade. O emprego da ama de leite foi trazido ao Brasil através dos portugueses. Esta, geralmente, era uma mulher negra, escrava e recém-mãe (SCHMITT, 2008). Já na Europa, essa mulher não era escrava, mas uma mulher de classe menos favorecida economicamente, especialmente residente na zona rural (DONZELOT, 1986). A ideia que embasava tal prática estava relacionada com um entendimento europeu que via a amamentação como uma tarefa que não era nobre ou digna de uma dama, conforme diz Almeida (1999). Isso gerava, ainda, um sistema comercial envolvendo as amas, as quais, no Brasil, por serem escravas, não recebiam pagamento pelos cuidados prestados aos bebês.

Enquanto isso, os bebês das escravas negras, conforme a escrita de Civiletti (1991), viviam em condições diferentes: alguns eram carregados pelas mães enquanto trabalhavam; aqueles que frequentavam a casagrande contavam com melhores condições de vida até os seis anos de idade (quando passavam a ser tratados como os escravos adultos); e os bebês das escravas que se tornavam amas muitas vezes eram destinados à Casa da Roda dos Expostos, instituição que acolhia bebês deixados anonimamente por seus familiares.

Ainda que, conforme Torres (2006), já existissem outras instituições de acolhimento às crianças, a Casa da Roda dos Expostos começou a se desenvolver na Europa, no século XVII, chegando apenas no século seguinte ao Brasil, onde teve seu fim somente na década de 1950. A instituição tinha esse nome por conter um cilindro onde os bebês eram depositados para que o anonimato dos adultos que os deixavam fosse assegurado. Segundo Torres (2006), tais instituições vinham a dar conta de questões sociais e morais, pois a maioria dos acolhidos provinha de mães solteiras, de pais que faleceram ou que não tinham condições de criá-los, de relações adulterinas e de escravas que os queriam livres. Por isso, Civiletti (1991) afirma que o maior número de expostos provinha das escravas.

Embora em péssimas condições, após a criança ser acolhida nessa instituição, como detalha Marcílio (1997), eram tomadas as atitudes básicas de registro e verificação das suas condições de vida, além do batismo. As crianças ficavam sob o cuidado de amas de leite e lá permaneciam até os sete anos de idade. Em seguida, as instituições buscavam famílias que as aceitassem como aprendizes de algum ofício (meninos) ou como empregadas domésticas (meninas). Mesmo assim, a maioria delas (sem contar o grande número de crianças mortas) acabava ou sob a condição de escravismo ou desamparada nas ruas, 
recorrendo a esmolas, pequenos furtos e prostituição para sobreviver.

Dadas as péssimas ou inexistentes condições de saneamento e procedimentos médicos, era frequente que bebês e crianças pequenas, tanto os que estivessem com as amas quanto os que estivessem sob os cuidados das Rodas dos Expostos, viessem a morrer. Por conseguinte, a expectativa de vida da população infantil não poderia ser muito alta. Nesse período, as mulheres passavam por muitas gestações, das quais poucas crianças viriam a crescer - o que era (e em muitos casos ainda hoje é, especialmente em grupos mais pobres da população) interpretado como a vontade de Deus. Na Europa e, posteriormente, no Brasil (fim do século XIX e início do século XX), a preocupação com a erradicação da mortalidade infantil foi se constituindo aos poucos, também pelo que Donzelot (1986) denomina a conservação ${ }^{2}$ das crianças.

Vailati (2006), ao estudar um ritual comum entre as famílias mais abastadas de São Paulo e do Rio de Janeiro, no século XIX, que era a prática de fotografar os "anjinhos", ou seja, as crianças que haviam falecido, percebeu que, no início desse costume, o importante era ter o registro da criança, algo que era caro na época. Talvez, esse momento fosse a única e última oportunidade para a família poder guardar uma lembrança de um filho ou filha (VAILATI, 2006) ${ }^{3}$. Por isso, bebês e crianças eram fotografados sem nenhuma preocupação em mostrar que estavam mortos, ainda que fosse feito um preparo de vestimenta e ritual para a fotografia a fim de retratar a criança pela imagem de um anjo, que poderia, conforme acreditavam, interceder pela família. Tempos depois, já eram perceptíveis esforços para esconder ou minimizar o fato de que se tratava de uma criança morta. Com isso,

no primeiro caso, não era tanto o desejo de restaurar o aspecto da criança de quando esta era viva, mas sim de utilizar o cadáver como materialização simbólica do novo estatuto espiritual da criança; aqui, parece que a intenção é sobretudo recuperar o aspecto da criança quando ela estava viva (VAILATI, 2006, p. 66).

Percebe-se um novo sentimento, ao menos em tal grupo social. Segundo o autor, tem-se agora uma valorização da família nuclear, a qual deve sustentar determinados sentimentos - inclusive os de dor e perda

\footnotetext{
2 Intervenção do Estado para construir a ordem social na França do século XVII até o século XX, com medidas morais e educacionais, propostas pelo próprio Estado, por meio das famílias, voltadas à negação das influências da criadagem dentro das classes ricas e, dentro das classes pobres, voltadas a "civilizar" e submeter os indivíduos às leis e à ordem.

3 Todavia, é importante destacar que a história não é linear e que essas práticas do século XIX ainda são presentes em alguns estados brasileiros com altos índices de mortalidade infantil, no século XX, como atesta o documentário gaúcho "A invenção da infância" (2000), dirigido por Liliana Sulzbach.
}

da criança. Além disso, Vailati (2006) ainda pontua que há a defesa da criança, na medida em que se passou a encarar a mortalidade infantil como um crime contra a nação, não mais como um fenômeno natural, contribuindo para a extinção do uso das fotografias das crianças mortas.

A prática das amas de leite também foi caindo em desuso entre o fim do século XIX e o início do século $\mathrm{XX}$, com o intuito de diminuir os altos índices de mortalidade infantil, o que passou a ser desejado tanto pela percepção de que o crescimento populacional virou uma questão de segurança nacional, podendo garantir a vitória em uma guerra, por exemplo (MARQUES, 2000 apud MAGALHÃES, 2011), como pela percepção da criança enquanto possuidora de um valor mercantil; isto é, uma riqueza econômica em potencial (BADINTER, 1985; DONZELOT, 1986).

Para abolir a prática das amas, foram sendo construídos saberes e argumentos que as apontavam como fazedoras de anjos ou as culpabilizavam. Segundo Donzelot (1986), a importância das nutrizes (amas de leite) foi diminuindo, tendo a medicina da metade do século XVIII, na França, desestimulado as práticas de amamentação de bebês por mulheres de aluguel. Zamith, em 1869, no Brasil, afirmou que as amas nunca poderiam nutrir bem uma criança tendo a lembrança de seu próprio filho (geralmente levado para longe dela) ou exercendo tal atividade contra sua vontade. Outros argumentos eram encontrados em guias maternos da época, nos quais era exposto que através das amas poderiam ser transmitidas doenças e valores morais inapropriados, além de representarem um risco à higiene (MAGALHÃES, 2011). Assim, as crianças pequenas e os bebês passaram a chamar a atenção, por motivos aqui supracitados e por outros que serão elencados a seguir, relacionados a saberes especializados, os quais, através de ampla divulgação à população, introduziram outras práticas na sociedade ocidental.

\section{O BEBÊ DOS ESPECIALISTAS}

A partir dos novos ideais, passou a circular, então, a ideia de privatização: "O fechamento da família contra as influências negativas do antigo meio educativo, contra os métodos e os preconceitos dos serviçais, contra todos os efeitos das promiscuidades sociais" (DONZELOT, 1986, p. 23). Ainda segundo o autor, a medicina oitocentista, na França, tinha a preocupação de reavaliar a organização do corpo e culpar o sistema de criadagem pelos excessos de prazer e perversões do corpo de jovens e crianças. Por isso, tal ciência se aliou às mães de plantão, capazes de conter a criadagem e vigiar suas crianças com mais atenção (DONZELOT, 1986). Tudo isso estava relacionado à crença de uma 
marcha rumo à civilização ${ }^{4}$. Tratava-se de um controle da população, em que os pobres eram considerados uma ameaça (KUHLMANN JR., 1998) e um atraso à civilização ocidental.

Percebendo que as crianças poderiam ser uma porta de entrada de mudanças nas famílias, proliferaram-se em todo o Ocidente estudos e publicações sobre elas, sobretudo advindas do campo da Psicologia, pioneira a estudar os bebês e as crianças bem pequenas (PEREIRA, 2011), e da Pediatria. Esses estudos foram divulgados em guias maternos, impressos gratuitamente a fim de atingir todas as classes sociais (MAGALHÃES, 2011), e em exposições internacionais. Nestas, calcados no progresso, na técnica e na ciência, eram mostrados produtos e atributos de modernidade e provas de que as nações estavam se esforçando para o "concerto das nações civilizadas" (KUHLMANN JR., 1998, p. 75, grifos do autor).

É possível perceber que as práticas com relação aos bebês e às crianças começaram a chamar a atenção nas sociedades ocidentais. Porém, por mais que tenha sido uma forma de preocupação para com as crianças em tais sociedades, essa atitude

não surgiu por benevolência, mas por razões atreladas à estrutura social e à política, oriundas de uma necessidade de preservação da população e da produção de mão de obra para o novo sistema produtivo, para a guerra e pelo interesse de formar futuros homens guiados, sobretudo, pelos preceitos iluministas da racionalidade (SCHMITT, 2008, p. 20).

Assim, quanto mais se conheciam as crianças, mais práticas que atingissem os ideais da época poderiam ser propostas. Como disse Foucault (2012), a organização de um saber está ligada a toda uma série de processos sociais de um dado momento, seja de ordem econômica, seja das instituições, seja das práticas de poder. A Pediatria exerceu influência principalmente nas mães, através dos guias maternos, que ensinavam como bem cuidar os filhos; e a Psicologia definiu estágios de desenvolvimento e de aprendizagem a serem considerados desde a entrada das crianças nas creches.

Em ambas as situações, foram construídas certas visões sobre o bebê e sobre a criança que ainda hoje são tomadas como naturais, como se não fossem invenções da Modernidade: representações sobre o que seria uma

\footnotetext{
${ }^{4}$ Sobre o desenvolvimento dos modos de conduta, a "civilização dos costumes", enquanto algo não natural, ver Elias (2011). Para o autor, o conceito de civilização foi se desenvolvendo a partir da "mudança estrutural ocorrida em pessoas na direção de maior consolidação e diferenciação de seus controles emocionais e, por conseguinte, de sua experiência (como, por exemplo, na forma de um avanço do patamar de vergonha e nojo) e de sua conduta (como, por exemplo, na diferenciação dos utensílios usados à mesa) " (ELIAS, 2011, p. 216).
}

criança normal, dentro dos padrões (MAGALHÃES, 2011), e como ocorreria seu desenvolvimento, que deveria passar de um estágio considerado incompleto para um considerado completo, somente alcançado no futuro da vida da criança. Os estudos evolucionistas, presentes em diversas áreas, desde a Biologia, a Psicologia e a Medicina até a Antropologia, a Sociologia e a Educação, contribuíram com tal proposta ao partirem da ideia de que a sociedade percorreria uma trajetória linear e universal, a qual a conduziria a um estado de civilização e, assim, no desenvolvimento do indivíduo humano, o bebê estaria no estágio mais primitivo e incompleto, pois a ideia de evolução partiria das formas mais simples para as mais complexas (CUZZIOL, 2013).

Muitos dos conhecimentos que reforçam a ideia dos bebês como frágeis e dependentes foram formulados e divulgados pela necessidade de controle da mortalidade e da pobreza. Dentre esses conhecimentos se encontravam as práticas escolares e os saberes higienistas, estando estes voltados, como o próprio nome diz, à defesa dos hábitos de higiene como uma forma de prevenção de doenças e, consequentemente, de diminuição do número de mortes. Nas palavras de Mozère, tratava-se de um período cuja "preocupação primeira era o combate aos micróbios e a instauração da primazia da higiene" (2013, p. 33). Ainda hoje, encontram-se, em muitas creches, resquícios dessas concepções, como o fato de deixarem bebês isolados, sem interações (para evitar possíveis contaminações), ou a impossibilidade de serem feitas práticas pedagógicas que causem sujeira nas crianças ou no ambiente, o qual também é bastante planejado de forma a contemplar o ideal higienista.

Essas questões ainda são reforçadas pela concepção de um bebê como sendo um tubo digestivo (NEYRAND, 2000): um bebê que não possui sentimentos, não manifesta emoções, um bebê somente biológico, incapaz, desvinculado da cultura, cujas ações são consideradas reflexos. A esse respeito, Mozère (2013) esclarece que o corpo da criança era considerado e tratado como um organismo, cujo desenvolvimento era visto como previsível, como Piaget, Freud e Lacan afirmavam. Tratava-se de um organismo unificado e, assim, os cuidados eram padronizados e idênticos para as crianças de mesma idade. Elas não deveriam se desviar e era necessário que mantivessem a ordem (MOZÈRE, 2013). Para que isso fosse possível, eram necessários alguns comportamentos, os quais poderiam ser mais bem alcançados a partir de esforços das instituições e das mulheres, tornadas responsáveis pelo cuidado das crianças.

Mozère (2012) lembra que a avaliação dos especialistas significa um julgamento, o qual não abre espaço para a heterogeneidade: eles decidem o que é bom, 
certo e errado. Nessas lógicas binárias, a opinião dos especialistas torna-se muito forte, pois, segundo a autora, quando as ações, as situações e os comportamentos são julgados como apropriados, entende-se que as pessoas podem confiar neles (MOZÈRE, 2012), como se fossem verdades inquestionáveis em vez de construções que estabelecem determinados padrões e comportamentos esperados. Com relação à pequena infância, Chamboredon e Prévot (1986) apontam o quanto a Psicologia favoreceu a institucionalização e o aumento de preocupações referentes ao desenvolvimento psicológico da criança:

assim se constitui uma definição social da primeira infância e de suas performances, definição que se inscreve num cursus definido, recorte das idades as quais são atribuídos desempenhos determinados e medidos. O que não passava de um período indiferenciado de maturação torna-se um cursus cientificamente definido: idade de andar e idade de falar, uma idade do desenho, etc. (CHAMBOREDON; PRÉVOT, 1986, p. 43, grifos dos autores).

Percebe-se, portanto, o quanto a pequena infância é associada a diferentes marcos do desenvolvimento da criança, criando expectativas sobre o que ela deve conseguir fazer em cada idade, mesmo que tanto a idade quanto as expectativas com relação a ela sejam construções culturais (ARIÈS, 1981; ROGOFF, 2005). Ainda assim, esperava-se - e ainda se espera - que bebês e crianças bem pequenas atingissem determinadas capacidades ao chegarem a determinada idade ou até mesmo antes disso, como aponta Rogoff (2005), ao destacar a valorização da antecipação na sociedade ocidental. Vale salientar, para encaminhar a discussão ao próximo tópico, que coube às mulheres, especificamente às mães, a responsabilidade de garantir que o processo de desenvolvimento da criança ocorresse de forma mais adequada perante os padrões estabelecidos.

\section{O BEBÊ DAS MÃES}

Isso era desejado porque, dentre outros fatores já aqui apresentados, dessa forma era possível implementar hábitos desde a gestação e também dar à mulher um novo status social.

É possível perceber aquilo que Carvalho (1999) indica em sua escrita: as práticas de cuidado se formaram historicamente, não fazendo parte de uma suposta natureza, maternidade, feminilidade ou ainda necessidade intrínseca às crianças. Segundo a autora, com o isolamento familiar (ARIÈS, 1981) - ou privatização, como fala Donzelot (1986) -, as crianças e as mulheres ocuparam-se da vida familiar e das atividades domésticas, levando a criança a se tornar, paulatinamente, o centro da família, dando origem às modernas noções de cuidado, amor materno, escola e professor.

Os estudos divulgados na época preconizavam a relação mãe-bebê, ressaltando-a como essencial para o bom desenvolvimento do bebê. Schmitt (2008) destaca os escritos de Spitz e Bowlby que, a partir da metade do século XX, mostravam uma criança capaz de estabelecer vínculos, um bebê não somente biológico, o qual precisava de cuidados que fossem além dos dispensados a sua alimentação e higiene. Contudo, Schmitt (2008) lembra que esses vínculos seriam preferencialmente realizados pela mãe, considerada a mais adequada figura relacional. Esse ideal em torno da mãe gerava críticas aos estabelecimentos educacionais para as crianças de até seis anos de idade, sendo tais instituições julgadas como inadequadas, o que contribuía para o pouco ou nulo investimento nestas (SCHMITT, 2008).

Estabelece-se, pois, uma relação orgânica entre médicos e famílias com mais recursos econômicos, o que provoca um fechamento da família contra toda promiscuidade social, além de uma promoção da mulhermãe. Esta e também a família passam a ter uma utilidade educativa juntamente com os médicos na criação dos filhos contra, por exemplo, antigas estruturas de ensino, disciplina religiosa, bem como o hábito do internato (DONZELOT, 1986). A mãe era vista como uma aliada do trabalho médico por combater os saberes populares, das comadres e por assumir um novo poder na esfera doméstica, com maior importância dada às funções maternas.

Cada vez mais no século XVIII, a Medicina e a Filantropia vão fazendo parte das tarefas educativas e da infância ocidentais: a primeira instituindo um conjunto de conhecimentos e técnicas para tirar as crianças da influência dos serviçais e vigiá-las; e a segunda, a partir de ideia de uma economia social, buscando diminuir o custo social da reprodução dos pobres e obter um número desejável de trabalhadores com um mínimo de gastos públicos (DONZELOT, 1986). Com tudo isso, cria-se um cordão sanitário em torno da criança, no qual seu desenvolvimento é encorajado pela psicopedagogia e controlado por uma vigilância discreta.

Chamboredon e Prévot (1986) acrescentam outros elementos à análise. Segundo eles, foi ocorrendo uma redefinição do papel pedagógico da mãe nas classes mais altas. A partir da extensão de sua escolaridade, da penetração de um "modelo profissional" ligado a uma nova imagem das atividades femininas e, consequentemente, da liberação dessa mulher de grande parte das funções caseiras "tradicionais" (especialmente por conta dessa nova imagem e da racionalização do trabalho doméstico, unido a aparatos próprios para a sua realização), a mãe da classe alta foi se configurando como portadora 
de qualificação cultural capaz de exercer uma função pedagógica com relação às crianças.

Por outro lado, nas classes populares, como as mulheres não possuíam renda para comprar um papel social através do dote no momento do casamento, as tarefas domésticas apareceram como possibilidade de substituir uma despesa social por um acréscimo de trabalho que não era remunerado; como possibilidade de introduzir elementos de higiene na criação das crianças; e ainda como possibilidade de controlar o homem, prezando pelos valores do casamento, retendo toda a família no âmbito da casa. Dessa forma, o trabalho industrial feminino, fora de casa, era visto como antagônico às suas funções de mulher, portanto, uma necessidade ocasional e não como um destino normal (DONZELOT, 1986).

Vê-se que o ideal era que as mulheres permanecessem em casa, entretanto, tal permanência era vivenciada de forma diferente, pois, como Chamboredon e Prévot (1986) argumentam, mesmo que nas famílias pobres a mãe não trabalhasse e, por isso, tivesse tempo, ela era vista como tendo uma fraca competência cultural. É possível perceber que as concepções acerca do bebê, da criança e da mulhermãe, como os cuidados tidos para com a criança, foram inventados e modificados ao longo do tempo, sendo, portanto, aprendidos. Também é construção o sentimento de proteção, de amor, do que é permitido ou não, do que é considerado bom ou ruim, com relação às crianças. E com a escolarização da pequena infância não foi diferente, tendo sido, portanto, valorizada ou rejeitada de acordo com os interesses sociais, econômicos ou culturais em jogo.

\section{O BEBÊ DAS CRECHES}

Mesmo que as diferentes instituições de educação infantil tenham sido criadas no século XVIII, só encontraram condições favoráveis para sua consolidação e expansão na segunda metade do século XIX. Dentre essas condições, encontram-se o incentivo das exposições internacionais e o aumento da urbanização, decorrente da industrialização, o que resultou no acréscimo do índice de pobreza e de famílias que precisavam de outras instituições que cuidassem de seus filhos enquanto trabalhavam (KUHLMANN JR., 1998). Como se queria delegar às mães a tarefa de cuidar das crianças, a creche era vista como um mal necessário (VIEIRA, 1988), isto é, somente para as crianças cujas mães trabalhassem, as mães de famílias populares, vistas como incapazes de cuidar seus filhos de forma adequada.

Segundo Kuhlmann Jr. (1998), enquanto nos jardins de infância, que eram as instituições destinadas aos mais favorecidos economicamente, procurava-se ressaltar 0 aspecto pedagógico; nas creches, que se constituíram para as crianças pobres, pretendia-se realizar uma ação mais disciplinar e moralizadora capaz até de penetrar no seio familiar. Assim, partindo-se de uma concepção em que se tem o educar como neutro, positivo ou emancipador, só os jardins de infância foram considerados como sendo instituições educativas por excelência, cabendo às creches apenas o papel assistencial. No entanto, sob essa visão superficial, não se percebia o quanto o cuidado e o atendimento aos menos favorecidos consistiam em práticas educativas (nem que só objetivassem o controle social).

Naquela época, além de a creche ainda não ser um direito da criança, como é hoje assegurado pela Constituição (BRASIL, 1988), a ela se atribuía menor valor, o que fazia com que os bebês e crianças bem pequenas e pequenas fossem ainda mais desvalorizados. Kuhlmann Jr. (1998) aprofunda a questão, problematizando a divisão entre as propostas para as diferentes classes sociais, apontando que a pobreza passou a representar um problema social. Para diminuí-la, ampliaram-se os meios para atender às classes populares, sempre pensando no seu controle e na busca pela ideia de civilização - e ainda não se preocupando com o direito das crianças pelo atendimento em instituições educacionais coletivas.

A partir do século XVIII, continua Kuhlmann Jr. (1998), a pobreza passou a ser vista como condição natural, porém secular, que precisava ser combatida, visto que tomou posição de problema social. Devido a isso, disseminaram-se iniciativas de assistência compreendidas dentro da filantropia, firmando-se na ciência e na fé no progresso. Tal assistência era papel do Estado e, cada vez mais, de organizações privadas, mas, cabe lembrar, não era direito do trabalhador, e, sim, um mérito para os mais subservientes. Mozère, a respeito das creches, ressalta que

esses estabelecimentos, igualmente criados por outras instituições de caridade de todos os credos, visavam moralizar os filhos de operários, mas constituíam igualmente, para quem os patrocinava, uma marca de distinção em termos de prestígio e uma engrenagem nas relações extremamente complexas entre as diversas instâncias políticas, morais e religiosas. Para que uma criança fosse aceita na creche, deviam ser preenchidas certas condições: seus pais tinham de ser casados, sóbrios e gozar de excelente reputação (2013, p. 33).

Logo, a fim de erradicar o problema social que a pobreza passou a representar, ampliaram-se os meios para atender às classes populares, sempre pensando no seu controle e na busca pela ideia de civilização - e ainda não se preocupando com o direito das crianças pelo atendimento em instituições educacionais coletivas. A partir disso, Kuhlmann Jr. (1998) traz uma articulação entre três saberes que contribuíram para a difusão das 
creches, salas de asilo ou jardim de infância, isto é, para a assistência à infância: o médico-higienista, o jurídicopolicial e o religioso, os quais estão imbricados às instâncias políticas, morais e religiosas apontadas por Mozère (2013).

O primeiro, visto como incontestável, propunha sugestões que lidassem com a inspeção e o saneamento (para atingir a civilidade e a modernidade) e com a mortalidade infantil, como já dito. Já o segundo preocupava-se com a infância moral e materialmente abandonada, a fim de promover ações que levassem à cidadania, o que, por outro lado, refletia-se na segmentação dos menos favorecidos, vistos como ameaçadores. O terceiro tinha na Igreja a valorização de sua experiência secular na caridade, o que não poderia ser desconsiderado.

Concomitantemente, os crescentes saberes constituídos sobre as crianças, especialmente os da Psicologia, eram amplamente divulgados e sustentavam a importância da primeira infância no desenvolvimento do sujeito, implicando, portanto, cuidados especiais, que foram incumbidos às mulheres. Assim, segundo Chamboredon e Prévot (1986), a primeira infância foi descoberta também como "objeto cultural", reclamando cuidados para além dos orgânicos e dos afetivos, que, como colocam os autores, passaram a ser mais fortemente associados aos bebês.

Ou seja, os bebês ainda eram pouco compreendidos como relacionais e culturais, permanecendo no âmbito privado das casas, preferencialmente no escuro, enrolados e sem contato com o exterior, considerado contagioso. Além disso, o fato de haver uma idade para se escolarizar recebeu reforço da Psicologia à medida que esta estabeleceu etapas de aprendizagem. Assim, as práticas consideradas pré-escolares (dos jardins de infância) e escolares não condiziam com as necessidades dos bebês para aprender. Sendo que muitas experiências e determinados status só eram permitidos aos bebês quando eles atingiam determinada idade ou quando adquiriam certa habilidade ou característica, como a linguagem oral e o andar.

Porém, ainda que tais concepções estejam enraizadas socialmente, as condições não são mais as mesmas. A creche, por exemplo, não mais é um "estabelecimento de beneficência que tem por fim receber todos os dias úteis e durante as horas de trabalho, as crianças de dois anos de idade para baixo, cujas mães são pobres, de boa conduta e trabalham fora de seu domicílio" (A Mãe de Família, jan. 1879, p. 3 apud CIVILETTI, 1991, p. 36), com a função de moralização. Nem é uma instituição de menor valor: de mal necessário (VIEIRA, 1988), atualmente compõe, junto com a pré-escola, a primeira etapa da educação básica - dever do Estado e da família, e direito da criança (BRASIL, 1988; 1990).
Os direitos dos bebês ainda são muito relacionados aos direitos da mulher, seja enquanto gestante, seja enquanto mãe. Da mesma forma, seus direitos com relação à saúde ganham maior visibilidade em programas sociais do que aqueles com relação à educação institucionalizada, o que pode estar relacionado aos argumentos apresentados anteriormente neste artigo. Entretanto, a vaga em creche pública, hoje direito do bebê e de seus responsáveis, é dificilmente obtida em razão, sobretudo, da baixa oferta de vagas: somente $24,36 \%$ dos bebês e das crianças de até três anos de idade foram atendidos em creches públicas no Brasil, durante o ano de 2013 (RIO GRANDE DO SUL, 2015). Adverte-se que, com a necessidade de destinar novas vagas à pré-escola, a fim de cumprir com a nova legislação vigente (BRASIL, 2009) ${ }^{5}$, a situação possivelmente continuará precária (e tende de piorar) para os bebês. Por isso, urge compreender que seus direitos existem para que sejam usufruídos no presente, enquanto pessoas que são.

\section{BEBÊS DO SÉCULO XXI: DESAFIOS CONTEMPORÂNEOS}

Gradativamente e através de diferentes estratégias, as experiências de educação e cuidado das crianças de até seis anos de idade foram se uniformizando e buscando o mesmo fim, como era o ideal da Modernidade. Não se pode afirmar que se tratava de uma totalidade no Ocidente, porém são práticas que foram se reproduzindo, ou deixaram marcas até hoje. As análises de Darcy Ribeiro (1995) esclarecem que indígenas e negros foram, sobretudo por meio de mortes em massa, procedimentos escravistas e escolarização das crianças, de indianizados e dê africanizados. Foi, portanto, a cultura branca e europeia, ainda que abrasileirada, que prevaleceu e que foi mais uniformemente valorizada e transmitida.

A partir dessas práticas ocidentais, tinha-se, nas sociedades industrializadas, a concepção de um bebê pertencente ao âmbito privado, cujo parceiro relacional era a mãe. Tratava-se de um bebê que merecia total atenção e presença do adulto para se desenvolver, pouco se prezando que estabelecesse relações entre pares ${ }^{6}$. Todavia, recordando os estudos de Rogoff (2005), Gottlieb (2009) e de outros autores aqui citados, o desenvolvimento humano é biológico, psicológico, histórico e cultural. Em comunidades africanas, indígenas ou não industrializadas,

\footnotetext{
5 Fica estabelecida a "educação básica obrigatória e gratuita dos quatro aos dezessete anos de idade, assegurada inclusive sua oferta gratuita para todos os que a ela não tiveram acesso na idade própria", a ser implementado até 2016 (BRASIL, 2009, Art. 1ㅇ). Essa proposta foi incorporada à Lei de Diretrizes e Bases de 1996 (LDB 9.394/96), por meio da Lei no 12.796, de 4 de abril de 2013 (BRASIL, 2013).

6 Para Corsário, pares são "a coorte ou grupo de crianças que passam tempo juntas diariamente" (2009, p. 87-88).
} 
o bebê participa da vida social, envolvendo-se com muitos adultos e com crianças de diferentes idades, que, além de brincarem com ele, são responsáveis pelo seu cuidado (ROGOFF, 2005).

Isso permite inferir que outras relações são possíveis e importantes. Se as relações entre crianças não eram incentivadas, a questão não estava somente atrelada ao papel da mãe, mas também a possíveis crenças adultocêntricas (de que os bebês e as crianças bem pequenas não são capazes) e higienistas (de que doenças poderiam ser transmitidas entre elas). Mas a própria Psicologia, que contribuiu para essas crenças, foi se abrindo a outras possibilidades: Rogoff, por exemplo, é uma autora da Psicologia, mais especificamente com estudos situados dentro do campo da Psicologia Cultural, traçando importantes contribuições que ajudam a romper com tais crenças.

Rogoff e também antropólogos como Malinoviski (1997), Geertz (2008), Mead (1931), Gottlieb (2009), Nunes (2003) e Cohn (2009) despertam para a valorização de saberes e práticas de outras comunidades, não restritas ao mundo ocidental industrializado. Pode-se aprender com outras culturas e, assim, estranhar o que se tem pensado a respeito dos bebês e do que se tem feito para e com eles, bem como do que se permitiu que fizessem ou não. Podem-se, inclusive, encontrar outras possibilidades para (ré) pensar concepções a respeito das instituições de educação infantil.

Os bebês da creche, hoje, pertencem a diferentes classes sociais, raças, religiões, localidades, sexos, gostos, saberes, culturas. Atualmente, muitos dos bebês brasileiros não passam mais tanto tempo com suas mães são educados e cuidados por pais homens, por casais homo afetivos, por professoras e professores em escolas infantis, por irmãos e irmãs, avós e avôs, primos e primas, tios e tias, vizinhas e vizinhos; apresentam mais habilidade em lidar com a tecnologia e aprendem sobre esta mais facilmente do que muitos adultos; interessam-se por animais, por mexer na terra e na água - questionando excessos de cuidados higienistas; rompem com as determinações estabelecidas aos estágios de desenvolvimento, propondo outras lógicas; enfim, expressam suas necessidades e suas vontades e demonstram que são capazes e que se interessam pelos outros (sejam outros de mesma idade, mais novos ou mais velhos) e pelo mundo.

Para que se reconheçam essas e outras capacidades dos bebês, precisa-se observá-los, prestar mais atenção nas suas ações, buscar outros referenciais que garantam sua visibilidade nas práticas sociais, nos contextos educacionais e nas políticas públicas. Isso é importante para que se passe a compreender os "bebês como sujeitos da história e de direitos. Direito à proteção, à saúde, à liberdade, à confiança, ao respeito, à dignidade, à brincadeira, à convivência e à interação com outras crianças" (BARBOSA, 2010, p. 3).

Por fim, considerar esses outros olhares e concepções acerca dos bebês é algo que pode, ainda, romper com a ideia que tem sido atribuída ao processo educativo. Segundo Bárcena e Mèlich (2000), ao estudarem Arendt, o processo educativo tem sido compreendido como um sistema de fabricação, que considera que em algum momento há um estágio final, acabado e, assim, todos devem ser iguais e se tornarem sujeitos iguais. Fica, portanto, o desejo de se voltar a Arendt, assim como Bárcena e Mèlich fizeram, e recuperar, na imprevisibilidade do nascimento, a força da educação enquanto $a c ̧ \tilde{a} o$, em que a verdadeira capacidade humana de ação não pode ocorrer no isolamento, mas na relação com outros humanos - tenham eles a idade que tiverem.

\section{REFERÊNCIAS}

ALMEIDA, João Aprígio Guerra de. Amamentação: Um híbrido natureza-cultura. 20. ed. Rio de Janeiro: Fiocruz, 1999.

ARIÈS, Philippe. História social da criança e da família. Rio de Janeiro: Guanabara, 1981.

BADINTER, Elisabeth. Um amor conquistado: o mito do amor materno. Rio de Janeiro: Nova Fronteira, 1985.

BARBOSA, Maria Carmen Silveira. As especificidades da ação pedagógica com os bebês. In: Consulta pública para reflexão e construção de Orientações Curriculares para a Educação Infantil. Brasília: Ministério da Educação, Secretaria de Educação Básica, ago. 2010. Disponível em: <http://portal. mec.gov.br/index.php?option $=$ com_docman\&task $=$ doc download\&gid=6670\&Itemid=>. Acesso em: 2 fev. 2014.

BÁRCENA, Fernando; MÈLICH, Joan-Carles. La educación como acontecimiento ético: Natalidad, narración y hospitalidad. Barcelona: Paidós, 2000.

BRASIL. Constituição da República Federativa do Brasil de 1988. Disponível em: <http://www.planalto.gov.br/ccivil_03/ constituicao/constituicaocompilado.htm>. Acesso em: $15 \mathrm{dez}$. 2013.

BRASIL. Emenda Constitucional no 59, de 11 de novembro de 2009. Acrescenta §3ำ ao art. 76 do Ato das Disposições Constitucionais Transitórias para reduzir, anualmente, a partir do exercício de 2009, o percentual da Desvinculação das Receitas da União incidente sobre os recursos destinados à manutenção e desenvolvimento do ensino de que trata o art. 212 da Constituição Federal, dá nova redação aos incisos I e VII do art. 208, de forma a prever a obrigatoriedade do ensino de quatro a dezessete anos e ampliar a abrangência dos programas suplementares para todas as etapas da educação básica, e dá nova redação ao $\S 4$ 을 do art. 211 e ao $\S 3^{\mathrm{o}}$ do art. 212 e ao caput do art. 214 , com a inserção neste dispositivo de inciso VI. Disponível em: <http://www. planalto.gov.br/ccivil_03/constituicao/emendas/emc/emc59. htm>. Acesso em: 31 jan. 2014.

BRASIL. Lei no 8.069/90, de 13 de julho de 1990. Estatuto da Criança e do Adolescente. Dispõe sobre o Estatuto da Criança e do Adolescente e dá outras providências. Disponível em: <http://www.planalto.gov.br/ccivil_03/leis/L8069.htm>. Acesso em: 15 jan. 2014. 
BRASIL. Lei $n^{\circ}$ 12.796, de 4 de abril de 2013. Altera a Lei no 9.394, de 20 de dezembro de 1996, que estabelece as diretrizes e bases da educação nacional, para dispor sobre a formação dos profissionais da educação e dar outras providências. Disponível em: <http:/www.planalto.gov.br/ccivil 03/_ato2011-2014/2013/lei/112796.htm>. Acesso em: 31 jan. $201 \overline{4}$.

CARVALHO, Marília Pinto de. O "cuidado" escolar como forma histórica de relação adulto-criança. In: CARVALHO, Marília Pinto de. No coração da sala de aula: gênero e trabalho docente nas séries iniciais. São Paulo: Xamã, 1999.

CHAMBOREDON, Jean-Claude; PRÉVOT, Jean. O ofício de criança. Definição social da primeira infância e funções diferenciadas da escola maternal. In: Cadernos de Pesquisa, São Paulo, n. 59, p. 32-56, nov. 1986.

CIVILETTI, Maria Vitória Pardal. O cuidado às crianças pequenas no Brasil escravista. In: Cadernos de Pesquisa, São Paulo, n. 76, p. 31-40, fev. 1991.

COHN, Clarice. Antropologia da criança. 2. ed. Rio de Janeiro: Zahar, 2009.

CORSARO, William Arnold. Métodos etnográficos no estudo de cultura de pares e das transições iniciais da vida das crianças. In: MÜLLER, Fernanda; CARVALHO, Ana Maria Almeida. Teoria e prática na pesquisa com crianças: diálogos com William Corsário. São Paulo: Cortez, 2009.

CUZZIOL, Ana Paula Gomes. "Pequenos-gigantes" entre si: notas etnográficas acerca da capacidade e da disponibilidade dos bebês em viver sociocultural mente, 2013. Dissertação (Mestrado em Educação) - Faculdade de Educação, Universidade Federal Fluminense, Niterói, 2013.

DOLTO, Françoise. La cause des enfants. Paris: Éditions Robert Laffont, 1985.

DONZELOT, Jacques. A conservação das crianças. In: DONZELOT, Jacques. A política das famílias. 2. ed. Rio de Janeiro: Edições Graal, 1986.

ELIAS, Norbert. O processo civilizador. 2. ed. Rio de Janeiro: Zahar, 2011. Vol. 1: Uma história dos costumes.

FOCHI, Paulo Sergio. "Mas os bebês fazem o quê no berçário, hein?": documentando ações de comunicação, autonomia e saber-fazer de crianças de 6 a 14 meses em contextos de vida coletiva. 2013. Dissertação (Mestrado em Educação) Faculdade de Educação, Universidade Federal do Rio Grande do Sul, Porto Alegre, 2013.

FOUCAULT, Michel. A ética do cuidado de si como prática de liberdade. In: FOUCAULT, Michel. Ética, sexualidade, política. 3. ed. Rio de Janeiro: Forense Universitária, 2012.

GEERTZ, Clifford. A interpretação das culturas. 13. reimpor. Rio de Janeiro: LTC, 2008.

GOTTLIEB, Alma. Para onde foram os bebês? Em busca de uma Antropologia de bebês (e de seus cuidadores). In: Psicologia USP, São Paulo, v. 20, n. 3, p. 313-336, 2009.

INVENÇÃO DA INFÂNCIA, A. Direção: Liliana Sulzbach, Produtoras: Monica Schmiedt, Liliana Sulzbach. Porto Alegre: M. Schmiedt Produções, 2000. 26 min.

KUHLMANN JR., Moysés. Infância e Educação Infantil: uma abordagem histórica. Porto Alegre: Mediação, 1998.
MAGAlHÃES, Maria das Graças Sandi. Medos, mimos e cuidados - leituras úteis para educar as mães: os guias maternos brasileiros (1919-1957), 2011. Tese (Doutorado em Educação) - Faculdade de Educação, Universidade Estadual de Campinas, Campinas, 2011.

MALINOVSKI, Bronislaw. Os argonautas do Pacífico Ocidental - introdução: objeto, método e alcance desta investigação. In: Etnologia, Lisboa, n. s., n. 6-8, p. 17-37, 1997. (mimeo).

MARCÍLIO, Maria Luiza. A roda dos expostos e a criança abandonada na História do Brasil. 1726-1950. In: FREITAS, Marcos Cezar de (Org.). História Social da Infância no Brasil. São Paulo: Cortez Editora, 1997.

MEAD, Margaret. Growing up in New Guinea: a comparative study of primitive education. New York: William Morrow \& Sons, 1931.

MOZÈRE, Liane. Como acender ao desejo das crianças pequenas e como sustentá-lo? In: Pró-Posições, Campinas, v. 24 , n. 3 (72), p. 31-44, set.-dez. 2013.

MOZÈRE, Liane. Is experimenting on an Immanent Level possible in RECE (Reconceptualizing Early Childhood Education)? In: Indo-Pacific Journal of Phenomenology, South Africa-Australia, v. 12, p. 1-9, May 2012. Disponível em: <http://www.ajol.info/index.php/ipjp/article/view/ 94602/ 83973>. Accesso em: 20 jan. 2014.

NEYRAND, Gérard. L'enfant, la mère et la question du père. Un bilan critique de l'évolution des savoirs sur la petite enfance, 2. ed. Paris: Presses Universitaires de France, 2000.

NUNES, Ângela. Brincando de ser criança: contribuições da etnologia indígena brasileira à antropologia da infância. 2003. Tese (Doutorado em Antropologia) - Departamento de Antropologia, Instituto Universitário de Lisboa, Lisboa, 2003.

ONU. Convenção sobre os Direitos da Criança. 1989. Disponível em: <http://www2.camara.leg.br/atividade-legislativa/ comissoes/comissoes-permanentes/cdhm/comite- brasileirode-direitos-humanos-e-politica-externa/ConvDirCrian.html>. Acesso em: 4 fev. 2014.

ONU. Declaração dos Direitos da Criança. 1959. Disponível em: <http://www2.camara.leg.br/atividade-legislativa/ comissoes/comissoes-permanentes/cdhm/comite-brasileirode-direitos-humanos-e-politica-externa/DeclDirCrian.html>. Acesso em: 4 fev. 2014.

PEREIRA, Rachel Freitas. As crianças bem pequenas na produção de suas culturas. 2011. Dissertação (Mestrado em Educação) - Faculdade de Educação, Universidade Federal do Rio Grande do Sul, Porto Alegre, 2011.

PINO, Angel. As marcas do humano: às origens da constituição cultural da criança na perspectiva de Lev S. Vigotski. São Paulo: Cortez, 2005.

RIBEIRO, Darcy. O povo brasileiro - a formação e o sentido do Brasil. São Paulo: Companhia das Letras, 1995.

RIO GRANDE DO SUL. Tribunal de Contas do Estado do Rio Grande do Sul. Radiografia da Educação Infantil no Estado do Rio Grande do Sul em 2013. Porto Alegre: Tribunal de Contas, 2015. Disponível em: <http://www1.tce.rs.gov.br/ portal/page/portal/noticias_internet/textos_diversos_pente fino/educacaocapa2015.pdf $>$. Acesso em: 31 jan. 2015. 
ROGOFF, Barbara. A natureza cultural do desenvolvimento humano. Porto Alegre: Artmed, 2005.

ROSEMBERG, Fúlvia. Educação para quem? In: Ciência e Cultura, Campinas, n. 12, v. 28, p. 1466-1471, 1976.

SARMENTO, Manuel Jacinto. As culturas da infância nas encruzilhadas da segunda modernidade. In: SARMENTO, Manuel Jacinto; CERISARA, Ana Beatriz. Crianças e miúdos: perspectivas sociopedagógicas da infância e educação. Porto: Asa Editores, 2004, p. 9-34.

SCHMITT, Rosinete Valdeci. "Mas eu não falo a língua deles!": as relações sociais de bebês num contexto de Educação Infantil, 2008. Dissertação (Mestrado em Educação) - Centro de Ciências da Educação, Universidade Federal de Santa Catarina, Florianópolis, 2008.

TORRES, Luiz Henrique. A Casa da Roda dos Expostos na cidade do Rio Grande. In: Biblos, Rio Grande, n. 20, p. 103-116, 2006.
VAILATI, Luiz Lima. As fotografias de "anjos" no Brasil do século XIX. In: Anais do Museu Paulista, São Paulo, v. 14, n. 2, p. 51-71, jul.-dez. 2006.

VIEIRA, Lívia Maria Fraga. Mal necessário: creches no departamento nacional da criança. In: Cadernos de Pesquisa, São Paulo, n. 67, p. 3-16, nov. 1988.

WINNICOTT, Donald Woods. O brincar e a realidade. Rio de Janeiro: Imago, 1975.

ZAMITH, José Ribeiro dos Santos. Do aleitamento natural, artificial e misto em geral e particularmente do mercenário em relação às condições da cidade do Rio de Janeiro, 1869. Tese (Doutorado em Medicina) - Faculdade de Medicina do Rio de Janeiro, Rio de Janeiro, 1869. Disponível em: <http://babel. hathitrust.org/cgi/pt?id=ucm.5316073574; view=1 up;seq=1>. Acesso em: 19 fev. 2014.

Recebido em 07-03-2017.

Aprovado em 19-07-2017. 